\title{
Aproximación al Pensamiento Político de Danilo Zolo ${ }^{1}$
}

\section{John Fernando Restrepo Tamayo*}

Recibido: 07 febrero

Dictaminado: 09 abril

\begin{abstract}
Resumen
El pensamiento político de Danilo Zolo está configurado, inicialmente, por una completa crítica-analítica en clave realista de los procesos de globalización, donde se estudian a fondo las principales perspectivas y los matices más relevantes de las teorías cosmopolitas surgidas en los últimos dos siglos, y los intentos que, de facto, se han dado por parte de las principales potencias mundiales después de Westfalia, en busca del establecimiento de una paz global realizada y efectiva. Y, por otra parte, los riesgos e implicaciones de un proyecto de gobierno mundial que puja por salir del papel cada vez con mayor fuerza, o al menos es ésta la creencia dada; por un lado, la constatación de una anarquía estatal latente en el mundo actual y, por otro, la constante pugna, por parte de un buen puñado de los principales politólogos y estudiosos de la política actual, por el desmantelamiento del sistema de los Estados nacionales. Este artículo tiene por objeto hacer un registro de tales premisas a través de las cuales resulta posible y necesario leer una percepción crítica de los procesos actuales de integración internacional o ruptura.
\end{abstract}

Palabras clave: filosofía política, gobierno mundial, estados nacionales, Danilo Zolo

\section{Approach to Danilo Zolo's Political Thoughts}

\section{Abstract}

Danilo Zolo's political thinking is initially composed by a thorough critic-analytics of globalization processes tuned in a realistic key, where the main perspectives and more

\footnotetext{
* Investigador de Universidad de Medellín. jfrestrepo@uctem.edu.com

1 Este artículo tiene como referencia el trabajo entregado al Instituto de Filosofía de la Universidad de Antioquia para optar al título del Magíster en Filosofía Política.
} 
relevant hues of the cosmopolitan theories developed in the last two centuries are deeply studied, and the de facto aims on behalf of the world potencies after Westphalia searching for an accomplished and effective worldwide peace. And, on the other hand, the risks and implications of a worldwide government project that struggles stronger every time to get out of the texts, or at least that is what is believed; on one side, the verification of a latent State anarchy in the present world, and on the other, the constant conflict of a considerable set of the main political scientists and pundits of the present days for the dismantling of the national States system. This paper has the purpose of a recording of those premises through which is possible and necessary making a critical assessment of the present processes of international integration or breaking.

Key words: filosofía política, gobierno mundial, estados nacionales, Danilo Zolo

\section{Sumario:}

I Introducción; II Santa Alianza; III La sociedad de las naciones; IV La organizacion de las naciones unidas; $\mathrm{V}$ ¿Fracaso de las instituciones internacionales para el mantenimiento de la paz?; VI La guerra del golfo; VII ¿Una ética internacional?; VIII La civita máxima y el derecho cosmopolita; IX Una critica realista; X Desajuste normativo; XI; ¿Una sociedad civil global?; XII ¿Transito al cosmopolitismo?; XIII Conclusion; Bibliografía

\section{Introducción}

Danilo Zolo parece una voz solitaria y precursora. Solitaria, porque casi todos los intelectuales más importantes de la posguerra han hablado de la necesidad de integración. Han defendido el proyecto paneuropeo y han pasado de largo con posiciones tibias y frágiles sobre la estructura crítica y fascista que se esconde detrás de las tribunas de los procesos migratorios. Michael Mann (Mann, 2009) hablaba con fuerza del lado oscuro de la democracia. Decía que todo proyecto democrático escondía un plan B. Un plan de limpieza étnica. Durante la segunda mitad del siglo XX ese plan B tuvo lugar en Armenia, Yugoslavia, Rusia, Congo, Zaire, Uganda, Ruanda y Albania. Un plan B que se confirma cada vez que se erige un muro que trace distancias físicas, políticas, culturales y económicas entre un 
pueblo y otro. Un plan B que se confirma cada vez que las tropas marinas impiden los procesos migratorios en el Magreb. Un plan B que se confirma cada vez que los euro-ciudadanos van a las urnas a apoyar los proyectos ultranacionalistas de la extrema derecha. Precursora porque desde la publicación de su obra insigne: Cosmópolis: perspectiva y riesgo de un gobierno mundial (Zolo, Cosmópolis:, 2000) ha denunciado la estructura actual de las relaciones internacionales como una continuación de la Santa Alianza en la que las grandes potencias han orquestado un modelo político y económico al tamaño de sus necesidades y de sus ambiciones.

El objetivo de este escrito es presentar los puntos decisivos de su propuesta política con el ánimo de ofrecer al escenario académico una voz crítica sobre el libreto oficial a través de cual se reclama por la instalación de procesos de integración, confeccionados a la medida de la Unión Europea y de los Estados Unidos, en un mundo global y real polisémico, marginal, fragmentado y excluyente. Para lograr tal objetivo haremos una presentación sistemática y crítica de los términos y de las instituciones sobre las cuales Zolo ha edificado un modelo de comprensión social y político del mundo contemporáneo.

\section{La Santa Alianza}

Zolo explica de qué manera la Santa Alianza tiene sus orígenes en las Guerras Napoleónicas libradas a principios del siglo XIX. Considera que tales confrontaciones militares dieron lugar a un gran desequilibrio entre los Estados europeos que empezaron a romper sus relaciones estables hasta el momento edificado desde 1648 con la Paz de Westfalia. Este tratado de paz permitió, por vez primera, un acuerdo entre naciones en el cual los Estados soberanos sólo reconocían a la Iglesia o al Imperio como las autoridades supremas legitimadas (Zolo, Cosmópolis: , 2000, pág. 31). "De dicho acuerdo surgió la primera relación entre naciones modernas, mediante el cual una gran variedad de Estados soberanos no reconocía autoridad superior alguna a la Iglesia o al Imperio." (Zolo, 2000; 31). Afirma Charles Tilly que el tratado de paz, celebrado 
en Westfalia, al final de la guerra de los 30 años o guerra de religiones puede describirse como la piedra angular del nacimiento del Estado-Nación. Con la instalación de esta institución se cierra el ciclo que empieza con las comunidades políticas y se centraliza el poder en manos de un ejército profesional y un aparato burocrático que asegure la eficiente recaudación de los impuestos. Así es como tiene lugar un círculo virtuoso entre el pie de fuerza y el buen manejo administrativo del Estado. El pie de fuerza asegura el recaudo tributario y el recaudo tributario asegura la moral y la lealtad de la tropa. (Tilly, 1992)

Tras la derrota de Napoleón, las naciones vencedoras (Rusia, Prusia, Austria y Gran Bretaña) instauran el primer intento de un gobierno internacional, creando un gobierno congresual, establecido a término indefinido pero con un tope máximo de duración de veinte años, en el que cada una de las superpotencias se comprometía a organizar en su agenda congresos internacionales en los que habrían de tratarse temas referentes a la tranquilidad popular, a la prosperidad y mantenimiento de la paz internacional, con lo que, rápidamente, la Santa Alianza recibió a casi todos los Estados europeos, excepción hecha con la Santa Sede y con el Imperio Otomano, quienes no tenían gran interés en debatir las decisiones ya tomadas por las superpotencias de turno (Bremer, 2013).

De cualquier manera, con la Santa Alianza encontramos por primera vez en la historia una federación internacional llamada a la promoción y el mantenimiento de la paz entre los Estados y, aunque sólo duró un corto período (diez años), logró la creación de organizaciones especializadas para el tratamiento de cuestiones específicas que confluyeron en determinaciones decisivas como la abolición del comercio de esclavos.

Después de los Tratados de Paz de Westfalia se consolidó el Estado moderno centralizado, cuya característica esencial es la soberanía, lo que significa que no existe ningún orden jurídico estatal que normativamente se encuentre supraordenado al Estado Nacional, por lo que, siendo todos los Estados soberanos, están en el mismo plano de igualdad (Bremen, 2013; 15).

El fracaso y final de la Santa Alianza se da, en un primer momento, por el conflicto de intereses latente hasta entonces entre las dos principales potencias europeas, a saber, Gran Bretaña y Rusia. Este conflicto demostró estar por encima de los propósitos piadosos de una paz internacional; y, en segundo lugar, los 
deseos dinásticos por parte de las principales potencias -principalmente Rusia, Prusia y Austria- y las ideas liberales y nacionalistas cada vez más atractivas y aceptadas en el marco de los Estados europeos (Zolo, 2000).

\section{La sociedad de las Naciones}

Concluida la Primera Guerra Mundial ${ }^{2}$ (Hobsbawm, 2012), las naciones vencedoras: Gran Bretaña, Francia, Italia y Japón, se dieron a la tarea de volver a crear un ente encargado de velar por la paz mundial surgido de las cenizas de la Santa Alianza y así, en el año 1919 se realizó el Pacto de la Sociedad de Naciones (constituida formalmente en 1920), la cual, aunque tenía muchas de las características de la Santa Alianza, sí fue concebida como una organización internacional, dividida en instituciones con componentes específicos como una asamblea, un consejo, un tribunal de justicia internacional, y un secretariado que atendía una agenda permanente y no sólo a llamados de carácter congresual como su antecesora de las guerras napoleónicas (Preámbulo, 1919).

La Asamblea era constituida por un representante de cada Estado miembro (artículo $3^{\circ}, 1919$ ). En ésta, cada Estado miembro tenía un voto y todas las decisiones tomadas requerían de la unanimidad. Si se tomaban decisiones de carácter tal que pudiera verse afectada la paz entre los Estados, las partes implicadas no podían votar, para que éstas no terminaran haciendo efectivo el derecho de veto motivadas por el beneficio propio (Zolo, 2000).

El Consejo, por su parte, estaba conformado por una reducida lista de estados permanentes, constituida por las cuatro potencias vencedoras de la Primera Guerra Mundial y, añadidas posteriormente, Alemania y La Unión Soviética. Los demás estados eran miembros no permanentes elegidos por la Asamblea (artículo 4).En el Consejo, al igual que en la Asamblea, había un principio de unanimidad (artículo 15), aunque no dejaba de existir una marcada influencia de las principales potencias de turno - principalmente Gran Bretaña y

2 Afirma Hobsbawm que la denominación primera guerra mundial tiene ocasión porque es la primera vez que se agrupa al mayor número de potencias extrajeras en una confrontación bélica que sobrepasa la esfera física europea. (Hobsbawm, 2012, 37) 
Francia- lo cual no impidió que la Sociedad de Naciones tomara decisiones de vital importancia para la política internacional del momento como las medidas para asegurar la prevención de posibles guerras.

Para Zolo es fácil explicar el fracaso de la Sociedad de Naciones. Esto desde la idea original de la creación de la misma que tiene una intencionalidad menos piadosa que la que se muestra en el papel: las potencias vencedoras de la Primera Guerra Mundial necesitaban hacer sentir su fuerza como tales y mantener su lugar privilegiado, haciendo que las demás naciones - grandes y pequeñas- respetaran al pie de la letra los principios establecidos en el Tratado de Versalles y en los demás tratados que decretaron el fin de la guerra, fijando así las reglas de juego para el mantenimiento de la paz a los demás países.

La incapacidad de la Sociedad de Naciones para cumplir su potencial como embrión de un gobierno internacional es fácilmente explicable por la tendencia obsesiva de las grandes potencias, especialmente de Francia, de utilizarla como un medio para preservar de forma eficaz es statu quo (Zolo, 2000: 34).

Por otra parte, y al igual que en la Santa Alianza, la brecha entre los intereses de las principales potencias fue tan grande que la Sociedad de Naciones terminó por paralizarse al ritmo que acrecentaban las tensiones entre éstas. De tal forma que la organización perdió credibilidad con tal rapidez que no pudo atender el desastre acaecido con las constantes violaciones al orden internacional del momento, concluyendo con el inminente fracaso del segundo intento -ambiciosodel establecimiento de la paz mundial.

A resultas de ello, una larga serie de gravísimas violaciones del orden internacional recibieron una legitimación tácita por parte de la Sociedad: Italia pudo ocupar la isla griega de Corfú, los japoneses invadieron Manchuria y China y se sucedieron las infracciones por parte de Alemania del Tratado de Versalles, en una cadena de acciones que culminó con la invasión de Polonia en 1939. Las sanciones decretadas contra Italia por su agresión hacia Etiopía, país miembro de la Sociedad de Naciones, quedaron deliberadamente sin efecto. La expulsión, por último, de la Unión Soviética, en diciembre de 1939, por su ataque sobre Finlandia no tuvo ni podía tener ninguna consecuencia: la Segunda Guerra Mundial acababa de estallar y la Sociedad de Naciones se podía considerar ya un organismo muerto (Zolo, 2000: 35). 


\section{La Organización de las Naciones Unidas}

Las Organización de las Naciones Unidas (ONU) marca el fin de la Segunda Guerra Mundial y recoge muchas de las principales características de sus antecesoras. Con algunos cambios en el programa y una nueva asignación de poderes a los organismos que la conforman, la ONU se crea en 1945 con el llamado hecho a los Estados por Roosevelt, Churchill y Stalin, quienes propusieron la Carta de creación del nuevo organismo con una gran cantidad de no negociables (Zolo, 2000).

Cincuenta países atendieron al llamado con el fin de aceptar la viabilidad o decretar el fracaso de las líneas generales de la Carta que, como con la Santa Alianza y la Sociedad de Naciones, estaba diseñada para favorecer el poderío de las naciones organizadoras, lo que hizo imposible cualquier intento por parte de los demás Estados de limitar el papel decisivo y funcional sobre la organización por parte de las principales potencias.

Superando los no negociables que, como ha mostrado la historia, eran sólo un obstáculo inevitable, pero no determinante, para que se diera la creación de la ONU. El 26 de junio de 1945 se aprueba por unanimidad, y se firma por todas las delegaciones asistentes la Carta de las Naciones Unidas, "empezando a existir oficialmente el 24 de octubre de 1945, después de que la Carta fuera ratificada por China, Francia, la Unión Soviética, el Reino Unido y la mayoría de los demás signatarios." (Organización de las Naciones Unidas, s.f.).

La estructura de ésta, en apariencia y en esencia, no es muy diferente a la estructura de la Sociedad de Naciones. Está compuesta por la Asamblea General, el Consejo de Seguridad, la Secretaría, el Consejo Económico y Social, el Consejo de Administración Fiduciaria y la Corte Internacional de Justicia. Pero la gran diferencia con respecto a su antecesora radica principalmente en el gran poder que recibe la figura del Consejo de Seguridad con relación a la Asamblea General, que ya no posee un poder de orden vinculante y decisivo.

En las Naciones Unidas la totalidad del poder se concentra, por lo tanto, en un Consejo de Seguridad que, a diferencia del Consejo de la Sociedad de Naciones, no es un órgano estrictamente deliberativo. El Capítulo VII de la 
Carta de San Francisco, por ejemplo, está enteramente dedicado a especificar los poderes de mando y organización militar con que pueda contar el Consejo en los casos en que se opte por emprender una acción internacional coercitiva (Zolo, 2000; 37).

La Asamblea General de las Naciones Unidas, bajo ninguna figura, puede tomar parte en decisiones de carácter vinculante, con lo que sus tareas se limitan a establecer recomendaciones que, en ningún caso, el Consejo de Seguridad está obligado a poner en consideración. De este modo, la totalidad del poder termina siendo ejercido por el Consejo de Seguridad; y así se pensó, dado que, para las potencias creadoras de la Carta de las Naciones Unidas, la razón del fracaso de la Sociedad de Naciones había sido justamente la ausencia de poderes del Consejo que era su órgano principal (Organización de las Naciones Unidas, s.f.). Aquí se ve reflejado la crítica mordaz que hace Zolo a dichas instituciones internacionales, puesto que no se cuenta con plena independencia y neutralidad para tomar decisiones sensatas y justas para la humanidad.

Con la convivencia de las instituciones internacionales, el silencio encubridor de gran parte de los juristas académicos, la complicidad de los medios masivos de comunicación y el oportunismo de un número creciente de las llamadas ONGs que están al servicio de sus propios gobiernos y conveniencias (Zolo, 2007; 18).

\section{V. ¿Fracaso de las Instituciones Internacionales para el Mantenimiento de la Paz?}

Para explicar un poco el fracaso de los tres principales intentos de establecer de manera efectiva el mantenimiento de la paz a nivel mundial, Danilo Zolo propone un análisis de las principales cuestiones filosófico-políticas que subyacen al entramado de las tres iniciativas, partiendo de la idea de que en todas se encuentran rasgos comunes de los principios fundacionales del modelo 
cosmopolita de la Santa Alianza. Tales características son:

En primer lugar, otorgar el poder de promover y mantener la paz a una fuerza tan centralizada como un pequeño puñado de superpotencias. Esto convierte las propuestas de sistemas internacionales en propuestas cosmopolitas demasiado simples, de tal manera que al ser dos o tres potencias las principales poseedoras del poder -en muchos casos coercitivo-, las jerarquías entre las demás naciones se hacen "asimétricas y polarizadas." (Zolo, 2000)

En segundo lugar, los elementos federativos que debía tener un sistema cosmopolita se reducen a decisiones en las que se pone a consideración si los usos de fuerzas militares deben o no ser promovidos y recomendados, dejando de lado cualquier otra forma posible de cohesión entre los Estados y de cooperación internacional, lo que se traduce siempre en resolución de conflictos internacionales por medio de la intervención militar. (Zolo, 2000)

En tercer lugar y en la misma vía, cuando los Estados pierden su poder decisional federativo, pierden progresivamente su capacidad de ejercer su propia justicia, con lo que caen en la suerte de un sometimiento a un Leviatán Global, con lo cual quedan expuestos los principios de independencia y soberanía igualdad soberana- de los Estados modernos. (Zolo, 2000)

En cuarto lugar, la paz universal tendrá que estar supeditada "al congelamiento del mapa político, económico y militar" (p. 43) para garantizar la estabilidad del orden internacional, con lo que, nuevamente, se tiene una visión muy simple de Cosmópolis, donde "la paz no sólo se opone a la guerra, sino también a las nociones de cambio social, desarrollo y conflicto." (Zolo, 2000, 43)

En quinto lugar, en ninguno de los tres proyectos existe una teoría general acerca del mantenimiento de la paz. Aquí, Zolo deja por sentado que la finalidad, realmente pragmática, de estas organizaciones internacionales es poder realizar intervenciones militares o diplomáticas siempre que surja un conflicto, pero sin ofrecer atención alguna a la búsqueda de estrategias para la prevención de la guerra (Zolo, 2000).

En sexto lugar, ninguno de los tres proyectos está estructurado en bases filosóficas ni de teoría política alguna que sirvan de sustento y se presenten como un verdadero ideario de la organización internacional. La duda aquí es -Zolo lo propone y deja la pregunta abierta a la especulación- si tal hecho se debía a 
la escasez de una cultura política por parte de los creadores de las respectivas organizaciones, o a la actitud mediocre de la tradición filosófica europea en lo que respecta a los temas relacionados con la guerra y la paz.

Con esto, Zolo termina concluyendo la importancia de realizar preguntas tales como las referentes, en un primer momento, a los principios fundacionales de la organización internacional, y si son éstos los adecuados o no; luego, lo referente al orden centralista y realista del que han partido todas las propuestas de un gobierno mundial; $y$, en un último caso, se pregunta sobre los temas referentes a la condición utópica de una paz universal y duradera, dado el potencial de las fuerzas políticas que se encuentran en constante oposición en el mundo actual.

Todo este análisis del autor italiano estudiado, expresadas en gran medida en Cosmópolis, evidencian la realidad actual que, si bien el autor lo hizo en el ocaso de siglo XIX, no pierden vigencia actual.

La comunidad internacional no ha experimentado grandes progresos en su evolución desde la Santa Alianza a la Sociedad de Naciones y luego, a las Naciones Unidas. Los últimos dos siglos no han presenciado ningún incremento significativo en la eficacia o en la autoridad de las instituciones internacionales. No se ha logrado alcanzar ni la paz ni el orden mundial justo para las que fueron creadas oficialmente estas instituciones. Al mismo tiempo, la situación y estado del planeta ha ido tomando aspectos alarmantes (...) Las naciones del mundo gastan, cada minuto, cerca de dos millones de dólares en armamento, cada hora mueren 1500 niños por desnutrición, cada día se extingue una especie animal, cada semana más personas son encarceladas, torturadas y asesinadas o forzadas a emigrar, cada mes se añaden unos 8000 millones de dólares a la deuda acumulada -que se eleva actualmente a un billón y medio de dólares- de los países más pobres de la tierra, y cada año se destruye un área de selva tropical que equivale aproximadamente a la extensión de Corea (Zolo, 2000; 18).

\section{La Guerra del Golfo}


La guerra que marca su inicio en la mañana del 2 de agosto de 1990 con la invasión de tropas iraquíes sobre el territorio de Kuwait, que se libró con una fuerza de coalición investida por treinta y cuatro países, con Estados Unidos a la cabeza, y autorizados por las Naciones Unidas, representa para el hilo argumental de Danilo Zolo lo que él califica de flagelo y, además, como la primera guerra cosmopolita de la historia, "estamos en presencia de un proceso de transición de la guerra moderna a la guerra global" (Zolo, 2011; 67)

La guerra movilizó a más de medio millón de hombres y mujeres de las fuerzas estadounidenses y a cerca de 160.000 combatientes de unos veintisiete países aliados, que constituyeron en conjunto la mayor expedición militar de la historia de la humanidad (Zolo, 2000; 55).

¿Por qué flagelo? No sólo se trató de la cantidad de uniformados de todos los países aliados, que ya por sí sola es escandalosa, sino del poderío militar, por mucho, superior por parte de los Estados Unidos; todo esto hizo de esta guerra una verdadera matanza. Hasta la fecha, ni iraquíes ni occidentales se quisieron aventurar a realizar el conteo oficial de pérdidas humanas, pero -por las que Zolo llama fuentes fidedignas- se calcula que por los Estados Unidos sólo murieron 148 combatientes de los cuales 37 perecieron por fuego amigo, mientras por parte de Iraq hubo alrededor de 220.000 muertes, donde se incluye una gran cantidad de víctimas civiles (Zolo, 2000).

La guerra del Golfo se interpreta como el "crisol del nuevo orden mundial" (...), mostro a una comunidad mundial dispuesta a reprimir por la fuerza, con una intervención colectiva, un acto de agresión contra un estado miembro de las Naciones Unidas. En realidad, la guerra contra Irak se puede interpretar como la primera, la verdadera "guerra global" y, como tal, como el modelo de las "guerras globales" posteriores (...): 1. La guerra del Golfo no fue una guerra entre estados soberanos (...) 2. No fue una "guerra limitada" en el sentido, propio del jus publicum europaeum, de una guerra "ahormada" con procedimientos y vínculos jurídicos (...) 3. La guerra del Golfo una "guerra global" en el sentido de que las Naciones Unidas la legitimaron 
formalmente como una guerra de la comunidad internacional contra un país responsable de un grave delito internacional" (Zolo, 2011; 71-72).

\section{VII. ¿Una Ética Internacional?}

Hasta aquí, la preocupación central de los argumentos de Danilo Zolo van encaminados a resolver una cuestión de gran importancia, ya mencionada antes, a saber: el vacío teórico de la organización internacional. El argumento fundacional de la Santa Alianza y sus herederas no está soportado en una filosofía de no-violencia, ni propone salidas argumentadas a las cuestiones referentes a la prevención de la posibilidad de futuras guerras.

Movido por tal preocupación, Zolo enmarca de manera sistemática los fundamentos de una Ética Internacional que se establezca sobre los principios de una universalidad normativa -como todas las doctrinas éticas- que enmarque los principios que son comúnmente aceptados (Zolo, 2000), pero no los define en su totalidad ni justifica normativamente las razones por las cuales éstos deben ser observados.

Es decir, lo que aquí se presenta es una ética que habrá de ser estructurada sobre la consideración de las circunstancias del momento y el cálculo de los resultados que puedan salir de las decisiones tomadas por la organización internacional. Así, los sujetos del discurso moral, en la ética internacional, son los Estados, mientras los individuos pasan a un plano que apenas se toma superficialmente. Con esto, la tarea principal de la ética internacional se plantea en términos de eficacia; "en política internacional la elección moral debe ser compatible con sus costes; en otras palabras, debe tomar en consideración las consecuencias previsibles y buscar la eficacia; no puede, por lo tanto, ser una ética basada en principios o en intenciones." (Zolo, 2000; 99)

\section{La Civitas Máxima y el Derecho Cosmopolita}

Por lo dicho en el apartado de la Guerra del Golfo, se entiende que el mantenimiento 
de la paz se ha soportado históricamente en el establecimiento de una fuerza supranacional comandada por las potencias de turno; los resultados de la Segunda Guerra Mundial, el decaimiento de ciertas naciones y el impulso de otras, la caída del bloque económico europeo y, por supuesto, las posteriores políticas de reivindicación de la guerra, ofrecieron el escenario propicio para pensar ${ }^{3} \mathrm{y}$ prospectar $^{4}$ inmersos en una reivindicación de las lecturas kantianas. Esto es, el revestimiento de la Organización de las Naciones Unidas con una fuerza militar sin precedentes, que se perfilaba como un ente de extrema necesidad en la intervención sobre eventos y problemáticas que pongan en riesgo la seguridad de los Estados. Estas intervenciones de corte político, económico, social y militar se legitimaban bajo el aseguramiento del discurso de los derechos humanos. Una legitimidad que, grosso modo, ha sido otorgada por casi toda la comunidad internacional y, naturalmente, de las grandes potencias.

A su vez, las consecuencias directas e indirectas de la guerra han puesto de manifiesto el crecimiento de las instituciones internacionales y han depurado en la idea de la necesidad de las mismas. Dicha necesidad manifestada en el orden de la complejidad de los problemas que, cuando explotan en la sociedad globalizada, repercuten sobre todos los habitantes del mundo y se inmiscuyen en los ámbitos social-político-económico-cultural en todos sus niveles y subniveles.

La guerra moderna se ubica fuera de todo posible criterio de legitimación y legalización, más allá de todo principio de legitimidad o de legalidad. Es incontrolada e incontrolable por el derecho, como un terremoto o una tormenta. Después de haber sido considerada bien como un medio para realizar el derecho (teoría de la guerra justa) bien como objeto de reglamentación jurídica (en la evolución del ius belli), la guerra vuelve a ser, como en la representación hobbesiana del estado de naturaleza, la

\footnotetext{
3 Kelsen es uno de los pensadores que, desde el derecho, han nutrido su pensamiento desde la postguerra. En esa misma lógica encontramos a JürgenHabermas.

4 Los autores de postguerra son incontables en sus múltiples perspectivas: Stiglitz, Peter Singer, Danilo Zolo, Norberto Bobbio, Bovero. Para los intereses de este escrito se mencionan particularmente dos cuyas posturas mantienen un tinte o incluso una reivindicación kantiana; así, se señala la postura que desde el derecho positivo propone Kelsen y desde la filosofía crítica propone
} 
antítesis del derecho (Bobbio, 1984: 60)

Así, por ejemplo, en esta sociedad globalizada donde los medios de comunicación transmiten eventos casi instantáneamente para el resto de planeta, se establecen las premisas de una comunidad de interacción política (Sartori, 1997). Hoy, lo que ocurre en el medio oriente no pasa desapercibido en Europa y América, así mismo, lo que pasa en Latinoamérica no deja de saberse en los últimos confines del continente asiático.

Así pues, nos encontramos en un nuevo escenario: el de las relaciones internacionales en la puja del mundo globalizado. Y, dada esa reivindicación kantiana, de la que se hablaba inicialmente, ahora, en este contexto, donde la necesidad de reflexión toma un papel substancial desde la globalización del derecho, reluce por sí misma en un debate que paulatinamente ha recaído en la idea del absorbimiento de cualquier otro ordenamiento jurídico: una erga omnes, una lexmundialis; en otras palabras, un posicionamiento del derecho como génesis de una comunidad internacional confiada en términos tácitos a un organismo internacional. Un nuevo ordenamiento que reviste a las organizaciones internacionales existentes, sobre todo a las Naciones Unidas, como las llamadas a asegurar el orden político y jurídico por la complejidad de las problemáticas subyacentes. En esta línea es que se inscriben Jürgen Habermas desde la filosofía política (2000) y Hans Kelsen desde la reflexión jurídica.

Kelsen habla de un orden jurídico original, jerárquico, donde el reconocimiento de los poderes políticos y jurídicos de los Estados es parcial, esto es, donde la soberanía de éstos influye mas no afecta sustancialmente la autonomía de este orden jurídico - escalonado- global. El ordenamiento jurídico internacional es universal y objetivo, por tanto, las normas internas de los países deben ir en consonancia con las normativas internacionales. En el ámbito internacional interamericano existe un concepto relativamente nuevo que -mutatis mutandis- desarrolla la idea del jurista austriaco, llamado control de convencionalidad, el cual tiene las siguientes características.

a) Consiste en verificar la compatibilidad de las normas y demás prácticas internas con la Convención Americana de Derechos Humanos [CADH], 
la jurisprudencia de la Corte Interamericana de Derechos Humanos y los demás tratados interamericanos de los cuales el Estado sea parte; b) Es una obligación que corresponde a toda autoridad pública en el ámbito de sus competencias; c) Para efectos de determinar la compatibilidad con la $\mathrm{CADH}$, no sólo se debe tomar en consideración el tratado, sino que también la jurisprudencia de la Corte Interamericana de Derechos Humanos y los demás tratados interamericanos de los cuales el Estado sea parte; d) Es un control que debe ser realizado ex oficio por toda autoridad pública; y e) $\mathrm{Su}$ ejecución puede implicar la supresión de normas contrarias a la CADH o bien su interpretación conforme a la $\mathrm{CADH}$, dependiendo de las facultades de cada autoridad pública (Corte Interamericana de Derechos Humanos, s.f.).

Siguiendo con Kelsen, este propone pues un sistema jurídico como regulador de la conducta de los organismos internacionales. Un sistema donde todos y cada uno de los inscritos gocen de una igualdad de derechos a pesar de sus diferencias de poder y extensión (1944). En ese sentido, la libertad, al igual que la soberanía de los Estados $^{5}$ se debe al reconocimiento formal en una comunidad jurídica que está determinada por una igualdad normativa. Naturalmente, se deriva de la doctrina legal de la ilustración de la idea cosmopolita. Una postura que puso en entredicho el universalismo medieval por una visión moderna de los Estados independientes en el ámbito internacional.

Ahora bien, cabe acotar que es curioso observar cómo Kelsen, con toda la brillantez que lo caracterizó, huyendo de toda postura imperialista, termina defendiendo que la forma idónea de configurar el orden político internacional versa sobre el predominio del derecho internacional, en la rama de un pacifismo jurídico que termina por caer en una postura ético-política que propende por el desaparecimiento de las diferencias jurídicas, sin contemplar las repercusiones que dicho proyecto implica; una homogenización que, cubierta en la Teoría Pura del Derecho (1960), corre el riesgo de desdibujar las diferencias de tipo

5 Kelsen reduce su concepción de sujetos jurídicos a los estados que acatan y se suman al ordenamiento jurídico mundial. Este espectro es catalogado como reduccionista al no contemplar a ciudadanos o entidades transnacionales que versen sobre asuntos de índole no política tales como las organizaciones deportivas, económicas o sociales. (Kelsen, 1944) 
social, cultural y políticas de los Estados, las instituciones y la población que la conforma. El recurso argumentativo al que recurre Kelsen es el de reconciliar esa diferencia bajo el reconocimiento de los sujetos que, en términos jurídicopolíticos, se otorga formalmente -aunque de manera parcial- ante los ojos del sistema de justicia legal internacional. De esa manera se soluciona la disyuntiva entre la potencia del orden jurídico nacional con el supranacional (1960).

Ya que el ordenamiento de los Estados es parcial frente al ordenamiento de tipo global, Kelsen se apoya históricamente en la noción de imperium romanum que atravesó la Edad Media para dilucidar la idea del globalismo jurídico (Zolo, 2002). Desde esta perspectiva, Kelsen propone una teoría monista del orden jurídico que cobra vida en el desmantelamiento de la soberanía de los Estados particulares y de su ordenamiento (1960). La unidad correspondiente del derecho y la primacía del derecho internacional significan que el ordenamiento internacional incluye todos los demás ordenamientos independientes, entendido éste como ordenamiento jurídico original, originario, exclusivo y universal, del cual se desliga todo el andamiaje político para sustentar el orden social en sus múltiples niveles.

Se perfila entonces, el abandonar el inter-estatalismo para recaer en un cosmopolitismo. Se levanta entonces el derecho internacional como una carta jurídica vinculante, objetiva y universal que atienda no en clave regional, sino en clave mundial. Ahora bien, dado que Kelsen tiene que defender la juridicidad de su modelo, siguiendo su construcción teórica, admitirá que todo ordenamiento debe ser coercitivo para poder sustentar su legitimidad. En Kelsen no existe el derecho en ausencia de un ejercicio sancionador; uno que imprima derecho bajo la espada de la fuerza. Lo que presenta una contradicción evidente que rescata Danilo Zolo, a saber: en Kelsen hay una contradicción inescrutable entre la exigencia de que los sujetos también sean sujetos jurídicos y la idea de que la guerra se convierta de facto en una sanción justa (2000). Y ¿qué diferencia hay entre el terrorismo internacional y la guerra? ¿Qué sucede con el reconocimiento de los Estados como sujetos jurídicos y de la población civil cuando, a fuerza de imponer el ordenamiento internacional, la guerra termina convirtiéndose ya no en un elemento de poder coercitivo sino, más bien, de terrorismo? La consideración de la coerción como aspecto inherente del ordenamiento jurídico hace caminar 
por la cornisa sus pretensiones de darle pureza al derecho; cuando el derecho roza inevitablemente con el realismo político, una aseveración tan drástica se vuelve peligrosa.

Kelsen replicaría, convencido, que una actividad judicial supranacional tiene mayor injerencia en las dimensiones macro-estructurales de la guerra, más que cualquier influencia de la actividad diplomática política o económica (Anales de la Cátedra Francisco Suarez, 2002), pero ello constituye tan sólo una muestra fehaciente de que el austriaco: o bien padece de un optimismo normativo que lo hace pensar que es posible abolir la guerra, y de paso que desaliñar la carrera armamentista de cualquier Estado es posible bajo la consolidación del derecho, o bien, como ya se dijo, Kelsen no está midiendo la fuerza de sus aseveraciones y aspiraciones jurídicas ${ }^{6}$.

Es en ese sentido que Danilo Zolo expone su crítica al racionalismo kelseniano que subestima la relación entre las estructuras normativas y su estrecha relación con los procesos culturales y económicos. Al parecer el pecado más grande de Kelsen será siempre que pensando en una teoría pura del derecho aislada de la moral (1960), recae en el peligroso terreno de la violación sistemática de los derechos o, lo que es lo mismo, que el derecho como coerción termine legitimando el atropello y el abuso, en cualquier momento, contra cualquier comunidad política. Y que si bien Kelsen habla de una jurisdicción penal, una característica que versa sobre la eficacia del control social y cultural, ignora que el estadio del derecho del que habla se encuentra muy alejada, precisamente, de aquello que se supone está llamado a controlar (Zolo, 2000). Kelsen indica que el ámbito de validez del Estado "está delimitado por el derecho internacional desde el punto de vista territorial, personal y temporal" $(1960,172)$.

Ante esto se pregunta Zolo ¿cómo lograr que la intervención supranacional en asuntos estatales no termine convirtiéndose en violaciones sistemáticas de derechos humanos? ¿Cómo no caer en una despersonalización del derecho bajo

\footnotetext{
6 Si bien la administración de la guerra es uno de los elementos más recurrentes en la Teoría Pura del Derecho de Kelsen (Kelsen, 1944), teoría que se sostiene en la conformación de una liga permanente para el mantenimiento de la paz, la crítica realista de Zolo se inscribirá en la antinomia de, por un lado la justificación de la guerra bajo la salvaguarda del ordenamiento jurídico global y su centralización del poder, y el reconocimiento de los Estados como sujetos jurídicos.
} 
la visión de un ciudadano global, en un orden institucional mundial? (2011) Para llevar a la práctica un proyecto tal, las potencias deben abandonar su lugar de privilegio, primero, como presupuesto metodológico y, segundo, como presupuesto político legitimador (Zolo, 2000). Ahora bien, en un escenario ideal, incluso en el más liberal de los escenarios, la clave en la que se reconoce el cosmopolitismo debe existir una estricta consonancia entre una carta institucional global con fuerza coercitiva, donde la influencia político-económica de las grandes potencias no haga parte del rasero decisorio $\mathrm{y}$, antes bien, propendan por el financiamiento de estas nuevas instituciones llamadas tanto a administrar justicia como impartir orden a nivel mundial, algo, por demás, lejos de lograr. La detención del poder y su posterior financiamiento debe ser un asunto de extrema reflexión para el cosmopolitismo, se debe señalar los inminentes peligros que la defensa y promoción de un proyecto como estos alberga.

El cosmopolitismo impone una visión de sociedad civil global y Estado mundial que a su vez sostiene la pretensión de construir o promover una ciudadanía universal, constitucionalismo mundial y democracia transnacional, que acumula y concentra el poder en torno a un subsistema político de corte occidental y liberal. Tal cosmopolitismo resulta claramente intervencionista, autoritario, y abiertamente homogeneizador, en detrimento de la pluralidad de sociedades y formas de vida (Maya, 2009, 327).

Hay que advertir que no se trata de un peligro que versa sólo sobre la naturaleza de la guerra, se trata de un aspecto que atraviesa ámbitos incontables en la vida política y que sobretodo el proyecto cosmopolita es un proyecto que subyace de las potencias cuyo valor hegemónico institucional pretenden albergar, inicialmente, todos los sistemas jurídico-políticos actuales para, consecuentemente, invertir el orden en un sistema unidireccional de la asociación mundial. Amparado en el discurso de las Naciones Unidas, el cosmopolitismo niega el valor de los sujetos políticos inscritos en ella que, aunque revestida de un discurso democrático vinculante, sigue reproduciendo $\mathrm{y}$, peor aún, potenciando espacio-temporalmente la hegemonía y la superioridad de las potencias sobre los países ubicados apenas en la periferia de la injerencia política y económica (2000).

Si bien los defensores del cosmopolitismo aleccionan sobre las inexistentes posibilidades de un atropello cultural, político o armamentista; un orden jurídico 
de tan altas dimensiones e implicaciones sólo puede verse a la luz de una sospecha sistemática so pretexto de la ausencia de un organismo jurídico normativo que imponga un tanto de orden a las turbulentas relaciones internacionales actuales, o en una lectura más realista, deja de lado los dictámenes de organizaciones que se ocupan de casos puntuales: organizaciones políticas regionales, por ejemplo, UNASUR y CAN; organizaciones no gubernamentales o de injerencias políticas externas como las organizaciones defensoras de derechos de los animales; organizaciones deportivas, entre otras, dejando como meros actores simbólicos a sus integrantes.

Por ello es necesario pensar en la siguiente cuestión: ¿cómo es posible que los tribunales internacionales juzguen y obliguen a resarcir las violaciones sistemáticas y reiterativas de la guerra cuando las principales potencias -vencedoras históricamente hablando- son quienes financian y procuran mantener el ordenamiento de una guerra justa? Una respuesta que, antes de ser contestada, nos enfrenta a otra disyuntiva, o bien reivindica la idea kelseniana expuesta en Peace Through Law(Kelsen, 1944) de una organización, de una liga permanente para el mantenimiento de la paz donde la centralización del poder y su determinación sobre el uso de la fuerza contribuya a la paz y la seguridad, y la estabilidad de las relaciones internacionales, o bien que el proyecto cosmopolita amenaza la pluralidad política y las instituciones divergentes con un discurso homogeneizador anclado en la tradición política occidental, cuyo auge es el discurso de los derechos humanos.

Como una buena representación de La Escuela de Atenas (1509 a 1510), la famosa pintura de Rafael Sanzio (Urbino, 6 de abril de 1483 - Roma, 6 de abril de 1520), mientras los críticos realistas y neorrealistas del cosmopolitismo, como Zolo, señalan la tierra con el índice, escudriñando las posibles soluciones de las problemáticas con los recursos que se tienen a mano, sus defensores señalan hacia el futuro, por considerar que el modelo westfaliano se ha quedado corto ante las nuevas lógicas de las relaciones internacionales actuales y que, dada la naturaleza de dichas relaciones, es menester mirar al futuro y pensar en un nuevo orden que albergue la institucionalidad y legalidad desde el derecho. Arguyen que la lógica asimétrica y desajustada de las relaciones internacionales, que se abren paso en las negociaciones multilaterales, surgen bajo la ausencia de un gobierno 
centralizado, siendo natural el evidente desajuste entre naciones provocando la inhibición del desarrollo y la resolución de conflictos internacionales de manera pacífica.

La lógica del funcionamiento, actuación, legitimidad y objeto en el orden internacional se dan de forma aislada y en diferentes niveles. Es así como, frente a un asunto puntual, pueden existir diferentes instituciones, siendo unas más legítimas que otras; algunas encargadas de resolver particularismos, bien inmiscuidas en las de mayor legitimación, bien por fuera de ellas. Instituciones que actúan sobre territorios no delimitados claramente y cuya jurisdicción parece alcanzar su legitimación en el arbitrio político de las decisiones que toman los representantes inscritos en dichas instituciones que son, a su vez, unas más democráticas que otras. Esta complejidad es traducida como un anarquismo internacional ${ }^{7}$, como un orden primitivo que carece de una estructura explícita que regule las relaciones y donde, en lugar de ello, la interacción entre Estados se active en virtud del interés político, económico, territorial o natural sobre un recurso o coyuntura determinada. Todo ello, abalanzado sobre la discreción propia de los sujetos políticos inmiscuidos. Esa suerte de anarquismo internacional, donde no hay medios formales efectivos, ni mucho menos criterios legales en la toma de decisiones parece ser el elemento más contundente para defender el cosmopolitismo. Por este motivo, la desazón en el ámbito internacional no puede dejar de ser más que evidente y, por ello, se apunta hacia un sistema jurídico mundial, un orden político que sea óptimo garante de la paz, administrador de la economía, la justicia y los derechos (Zolo, 2000).

\section{Una Crítica Realista}

Ahora bien, ¿hacia dónde mirar? ¿Puede más el peso de las problemáticas actuales? ¿Es necesario fijar la vista hacia el futuro y abandonar de una vez la división territorial entre naciones para comprender esto bajo la lógica de una

7 Término acuñado entre muchos por Norberto Bobbio en su texto: El problema del positivismo jurídico (Bobbio 2006) 
liga de naciones? ¿Son los procesos de globalización de la vida internacional una muestra fehaciente de la necesidad de un tránsito de perspectiva, esto es, a una sociedad global y, si es así, debemos fijarnos en la postulación de proyectos cuya envergadura recoja todas las formas de administrar la justicia, la economía y hasta la forma de hacer y entender la política a una escala global?

En esta línea, el autor italiano prologando a Roger Campione en El nomos de la guerra advierte lo siguiente.

Podría decirse que el "renacimiento" de la doctrina del bellumiustum es una especie de prótesis ideológica que ha sido utilizada para justificar moralmente, y legitimar jurídicamente, las "nuevas guerras". En las últimas décadas el mundo ha pasado de la "guerra moderna" a formas de "guerra global", en sintonía con los procesos de creciente interdependencia económica y de concentración del poder político internacional en manos de algunas grandes potencias occidentales: son los fenómenos que han sido designados con el término eufemístico de "globalización” $(2009,11)$.

Si bien todas las preguntas anteriores no tendrían una respuesta contundente que diera lugar a futuras réplicas, por lo menos permiten introducir la crítica que emite Danilo Zolo y, dentro de ella, la advertencia de un asunto crucial en la comprensión del cosmopolitismo; esto es, la idea de que todas estas pretensiones universalistas no son más que una nueva expresión de la voluntad política de las grandes potencias de occidente de garantizar su discurso ético-político, amparado en una defensa de su tradición y de su potencial económico. Así lo expresa Zolo en el interesante diálogo que tiene con Negri en las Cinco lecciones en torno al Imperio.

El nuevo "orden mundial" impuesto por la globalización ha conducido a la desaparición del sistema westfaliano de los Estados soberanos. Ya no hay Estados nacionales, fuera de sus moribundas estructuras formales que sobreviven todavía dentro del ordenamiento jurídico y de las instituciones internacionales. El mundo ya no está gobernando por sistemas políticos estatales, sino por una única estructura de poder que no presenta ninguna analogía significativa con el Estado moderno de origen europeo. Se trata de un sistema político descentralizado y desterritorializado, que no responde a tradiciones y valores étnico-nacionales, y cuya sustancia política y normativa es el universalismo cosmopolita (Negri, 2004: 25). 
Para encaminarnos a un escenario cosmopolita generoso con todos los miembros de la comunidad internacional es necesario que las grandes potencias cedan sustancialmente ese puesto de privilegio que se han ganado, unos por vías de políticas económicas cercenantes ${ }^{8}$, otros por mantener una concentración de poder, otros bajo el afán de la carrera armamentista y militar, la intromisión en guerras civiles, explotación, obtención o administración de recursos naturales, y otros por todas o varias de las anteriores.

Sostener una estabilidad política, por ejemplo, como la entendía Thomas Pogge, a saber, la comprensión de los Estados de democracias fuertes como garantes del desarrollo económico e industrial, es por mucho una aseveración peligrosa. Las aspiraciones expansionistas de occidente, y su acostumbrada intromisión en asuntos de Estado bajo la batuta de la intervención humanitaria, las idea del aseguramiento de la paz, de exportarla por vías de imposición, cuya legitimación anclada en el desarrollo y la exaltación de la tradición políticoeconómica demuestra una actitud pretenciosa, maquillada de altruista por parte de las grandes potencias; una imposición donde, por medio de una pacificación forzosa, se cae en la peligrosa senda de la invisibilización etnográfica y cultural -por no decir política y económica- en su lado más institucional sino, también, la posibilidad misma de generar procesos y escenarios de resolución de conflictos entre los agentes inmiscuidos en la problemática misma (Zolo, 2000). Una injerencia e imposición de democracia que desbordó el principio westfaliano de no intromisión en los asuntos particulares de los Estados.

Al respecto, la ONU ha sido la institución por antonomasia llamada a ser la garante de la democracia, de impartir justicia a nivel internacional y de sentenciar acuerdos y decisiones políticas de ayuda, defensa o ataque sobre territorios aislados. Revestida de los derechos humanos, discurso que contempla, según los cosmopolitas, un manifiesto político donde cualquier comunidad étnica o política puede ver reflejada sus presupuestos básicos, se muestra en la escena internacional como una organización que, por su naturaleza y su concedida legitimidad, se roba

8 Pensar al respecto de la influencia del dólar estadounidense en las economía mundial y de sus repercusiones en las economías de América Latina o de la reprochable decisión de la Unión Europea de no seguir brindando un colchón de aire a la economía griega y portuguesa (País, 2015). Recuperado en octubre 20 del 2015 en el sitio web: http://www.elpais.com.co/elpais/economia/noticias/euro-debilita-ante-crisis-grecia. 
el centro de la discusión y de las decisiones (Zolo, 2006a).

No cabe duda que los derechos humanos reúnen una variedad de elementos que forman parte de la mayoría de las culturas -incluso de las no occidentales-.

Se podrá hablar de protección internacional de los derechos humanos de verdad sólo cuando una jurisdicción internacional consiga imponerse y superponerse a las jurisdicciones nacionales, y se realice el paso desde la garantía dentro del Estado que, todavía caracteriza predominantemente la fase actual, hasta la garantía contra el Estado (Bobbio, 1991: 37).

Ahora bien, allí donde se reduce el espectro y se particulariza el asunto, es donde se hace visible la dicotomía entre el discurso y valores del uno -el discurso de los derechos humanos comprendidos lógicamente como un discurso eminentemente occidental-, con el ethos del otro -alguna comunidad que se mantenga al margen de los derechos humanos-. Los derechos humanos remiten a la representación, al cobijamiento de una comunidad internacional, una civitas máxima; sin su fuerza no sólo no sería posible hablar del cosmopolitismo como teoría, sino que sería difícil prever cualquier movimiento a nivel transnacional. Pero con su importancia deviene su riesgo. Es curioso observar cómo el cosmopolitismo dogmatiza el discurso de los derechos humanos y termina convirtiéndose en un elemento de coacción. Una preponderancia del derecho cosmopolita sólo puede entenderse a partir de los derechos humanos y su inherente interpretación de los valores políticos occidentales. Pero, el riesgo lo constituye el hecho de pensar que, en un determinado escenario, reconocerlos, si se admiten todas sus pretensiones epistemológicas, no implica necesariamente su efectiva defensa y, con ello, en lo que se refiere a la violación sistemática de derechos humanos se introduce también la cuestión del hambre y la pobreza (Zolo, 2000).

Las grandes potencias han enmascarado sus guerras agresión como "intervenciones humanitarias para la protección de los derechos humanos". Estas formalizan la confrontación entre el particularísimo que emana del principio de la soberanía de los estados y el universalismo de la defensa internacional de los derechos humanos. Zolo cuestiona la validez jurídica 
del "derecho-deber a intervenir" y la "responsabilidad de proteger". En su opinión, la legitimación de la guerra humanitaria equivale a la negación de los derechos básicos [de la persona], comenzando por el elemental derecho a la vida (Castro, 2009).

El Consejo de Seguridad de las Naciones Unidas es muestra de ello donde, naturalmente, el poder militar y el uso de la fuerza, se delega de facto a las potencias y ciertas decisiones son descentralizadas. Es curioso observar cómo de la mano de mecanismos e instancias institucionales, propios de las organizaciones, el espectro democrático se va reduciendo de manera paulatina, y cómo ellas dan a luz a una serie de desajustes normativos; por ejemplo, el existente entre tribunales internacionales de justicia y el Consejo de las Naciones Unidas, que más allá de demostrar una inconsonancia latente entre instituciones administradoras de justicia, son pruebas irrefutables de muchas medidas que terminan beneficiando formalmente a algunos Estados y perjudicando a otros (Zolo, 2006). Así pues, si las agregaciones, del tipo que sean -regionales o supranacionales- no defienden los intereses políticos o las aspiraciones económicas de otro, sí perjudican mínimamente, y aunque de forma indirecta, a algunas de las naciones rectoras del orden internacional, no sólo no podrán absolver todas las funciones que están llamadas a ejecutar, sino que estarán destinadas a un fracaso sistemático, y hasta en un veto político en el más drástico pero posible de los escenarios. Este desajuste es leído por los cosmopolitas en la ya nombrada clave de un anarquismo internacional, pero su contestación es la ley del talión: esto es, atacar los desajustes de poder con una mayor concentración del poder (Zolo, 2000). ${ }^{9}$

Los cosmopolitas encuentran que la pluralidad de los Estados y del ejercicio de su libertad, soberanía e independencia, la diferencia de costumbres y sistemas políticos estimulan la presencia de futuras guerras, en contraposición de un sistema unidireccional donde se limite la domestic jurisdicción. La crítica de los realistas, por otro lado, propende por una reivindicación del problema del orden y la paz internacional; pero es una crítica que trata de exhumar los fenómenos actuales no a la luz de un proyecto esperanzador, sino de una perspectiva mínima del poder,

$9 \mathrm{Al}$ modelo iusglobalista que reviste el discurso cosmopolita se le puede oponer la idea expuesta por Bull en Theanarchicalsocietyde un orden político mínimo(Bull, 1977) . 
una visión netamente liberal, en la medida en que se considera la concentración del poder como un asunto que pone en riesgo la autonomía -el poder y la soberanía de los Estados por un lado y, por otro, el reconocimiento de la categoría jurídica de los ciudadanos-. Se parte del señalamiento de la centralización excesiva del poder como un asunto de extrema injerencia donde los Estados van perdiendo cada vez una mayor importancia en el escenario internacional y donde el orden, la paz, y la estabilidad de las relaciones internacionales no se ejerzan por medios coercitivos jurídicos (Zolo, 2002). En otras palabras, donde un orden jurisdiccional no se levante frente al discurso negativo de la violencia, del uso regulativo y de la intromisión a golpe y espada, como legítimamente se ejercía en el Medioevo con la Civitas Maxima, una idea que aunque cobra valor como referente histórico, lo es mayor aun en la medida en que nos advierte de sus conocidas consecuencias.

Una guerra librada por un organismo cuya legitimidad es de orden global no puede más que ser un peligro mayor que aquellas que la historia nos ha ofrecido. Los hechos inmersos en la guerra, tomando como referentes la Guerra del Golfo y la Segunda Guerra Mundial, nos dictan que se trata de más que una simple disputa bélica. Se trata de lo que Walzer denominaba una guerra justa contra un enemigo injusto (1997); hablamos de algo más que de tildar a un enemigo, sino que se interpreta como una guerra moral entre buenos y malos, jurídicamente injusta, donde la violación de los derechos humanos, como consecuencia del resultado de la guerra sólo puede recaer, en términos de responsabilidad jurídica, sobre el título de los vencidos, fenómeno tal, que quizás se agudice con la centralización de un ente administrador de justicia global.

La doctrina de la "guerra justa", en definitiva, en vez de conseguir "hacer ganar a quien tiene razón” - éste debería ser el objetivo de cualquier procedimiento arbitral correcto- ha sido excogitada y hoy es replanteada por las grandes potencias para "dar la razón a quien gana". Ni siquiera la legitimidad moral de la guerra de defensa de un Estado agredido por otro Estado, argumento central del ius ad bellum, sobrevive en época nuclear, después de Hiroshima e Nagasaki (sic). A estas alturas, la misma distinción entre guerra defensiva y guerra ofensiva es borrosa (Campione, 2009: 17). 
En palabras del mismo Zolo, "detrás de toda guerra se ubica la imposición y la invisibilidad del contrincante como sujeto, y la negación de su identidad histórica" (Zolo, 2004).

El concepto tradicional de una guerra justa implica la canalización de la guerra y su elogio como un instrumento ético, dos ideas que el pensamiento político moderno y la comunidad internacional de los Estados-nación habían repudiado resueltamente. Estas dos características tradicionales han reaparecido en nuestro mundo posmoderno: por un lado, se reduce la guerra a la condición de acción política y, por el otro, se sacraliza el nuevo poder que puede ejercer legítimamente funciones éticas a través de la guerra (Negri, 2002: 29).

\section{Desajustes Normativos}

Para Falk y Cassese el modelo de la Carta de las Naciones Unidas constituye un monstruo normativo, que propende por una defensa y promulgación de los intereses de las grandes potencias y que, por ende, pierde toda categoría de justificación jurídica -eso sin contar la justificación de la acción bélica- (Zolo, 2000). Ambos pensadores arguyen que el derecho liberal contemporáneo hizo añicos la igualdad de los Estados o, lo que es lo mismo, asumió la desigualdad entre Estados como un presupuesto que no altera la legitimidad en las relaciones entre los mismos y, a su vez, implementa paulatinamente el discurso de la legitimación de la fuerza cuando alguna amenaza -interna o externa- irrumpe con la paz o la estabilidad decretada. Si los hechos sólo muestran que el derecho internacional, que asume dentro de su modus operandi la incontenible desigualdad entre los Estados, atropella a los mismos, dejando la autonomía a las grandes potencias, el postulado de una teoría jurídica global sólo puede traducirse en simples visiones y fantasías del mundo que quisiéramos tener.

Los procesos de desajuste normativo han demostrado, a su vez, un desajuste funcional y una seria diferencia jerárquica entre el poder normativo y el coercitivo de los Estados nacionales, y las nuevas dimensiones de los 
problemas que se acumulan en la agenda internacional (Zolo, 2000). La Carta de las Naciones Unidas constituye un buen ejemplo de ellos, donde las normas fundamentales imponen obligaciones y las normas secundarias quedan al arbitrio de la interpretación (Zolo, 2006a).

El Banco Mundial y el Fondo Monetario Internacional no escapan a los desajustes normativos. Tanto el uno como el otro obedecen y se subordinan a las tendencias de la economía mundial. Su papel como las instituciones internacionales más relevantes es apenas parcial, ya que se han visto subordinadas por la economía de las potencias que son quienes las financian. Las medidas económicas impuestas sobre el pago de la deuda de los países pobres, taza que ha ascendido en un 17\% (UNDP, 1994) (Helleiner, 1992) (Instituto de Estudios Políticos para América Latina y África, 2016), hacen que estos países dejen de invertir en políticas de desarrollo social.Anthony Giddens (2000), afirma que debe abandonarse la idea de que las medidas surgidas para la burocracia internacional pueden tener un efecto positivo en el desarrollo social humano. Y es que, es más que obvio, desde que el proyecto cosmopolita brote de lo que Zolo denomina un prejuicio europeo, esta defensa será la de una tradición que se ha mantenido al punto del hermetismo frente a otras culturas; entonces se trata de un proyecto cuya universalización no negocia valores sino que eleva a categoría vinculante los preceptos de la cultura propia (Zolo, 2000).

La estructura básica de un proyecto como el cosmopolita es consecuentemente jerárquica, si bien se habla de la necesidad de la igualdad formal de los sujetos, ésta está lejos de ser cierta. También lejos parece la no intromisión en asuntos de injerencia nacionales por parte de las instituciones transnacionales justificada en la fuerza coercitiva de los derechos humanos, el estrechamiento de la brecha entre países pobres y ricos y la influencia político-económica de las grandes potencias, primeras defensoras del cosmopolitismo y rectoras de las reglas, lógicas y operatividad de las relaciones internacionales.

Mientras el pacifismo y optimismo kelseniano terminan abandonando al Estado y apuntan hacia la reforma sustancial de las instituciones internacionales, Habermas (1999), en lo que se refiere al cosmopolitismo kantiano, termina confiándose de las inminentes consecuencias de revestir a las Naciones Unidas con un poder tal. No se puede pensar en el estiramiento de las funciones de la 
ONU sin solucionar, en primer lugar, problemáticas puntuales sobre el futuro del intervencionismo humanitario, que puede terminar por ser una amenaza al pluralismo como una forma de homogenización.

La doctrina y la práctica de la guerra humanitaria fueron, en realidad, el primer paso de un recurso sistemático a la fuerza militar de una superpotencia "imperial" que pretende imponer su hegemonía económica, política y militar a todo el planeta con métodos terroristas. Las guerras humanitarias fueron un preludio de las posteriores "guerras preventivas" contra Afganistán, Irak y, probablemente, de la que se anuncia contra Irán ${ }^{10}$. Una vez más se confirma la máxima enunciada por Proudhon y recogida por Schmitt: "El que dice humanidad trata de engañarte" (Zolo, 2011: 90).

La paz no puede lograrse exclusivamente a través de términos legales e institucionales (Zolo, 2000). Es claro que la guerra como fenómeno que toca sensiblemente todos los aspectos de la vida humana no puede ser relegada a un tratamiento unidireccional como lo es el pacifismo jurídico, cuyo valor supremo son los derechos humanos. Se trata entonces de una comprensión cuyo sesgo sólo terminaría fragmentando los conflictos mismos, cerrando la puerta a posibilidades alternativas para resolver las problemáticas presentes. El pacifismo jurídico institucional, no toma en cuenta el aspecto sociológico de la violencia ni las consideraciones sobre ética y moralidad. Una visión realista de la guerra implica admitir que los humanos, como muchos animales, son agresivos; esto es, ir más lejos que una prohibición o negación terminológica o una normativa.

En lugar de estas estructuras jerárquico-militares, mejor trabajar sobre estructuras sociales y técnicas débiles de reconciliación (Zolo, 2000) -tan oportuno para el caso colombiano sobre el postconflicto (postacuerdo) que se avecina. Sólo se habla de la guerra, la negociación y el establecimiento de la paz con sujetos políticos legitimados, pero ¿qué pasa entonces con aquellos sujetos que dentro del orden político no tienen personalidad jurídica? Por esa razón Danilo Zolo comprende que debe haber un giro epistemológico en el abordaje y valoración de la guerra donde la intromisión como resolución en conflictos, o las medidas económicas cercenadoras, no constituyan el único recurso a la

10 La tensión entre Irán y la comunidad internacional ha bajado de nivel por el reciente acuerdo entre aquel país y el Organismo Internacional de Energía Atómica (OIEA) que levanta las sanciones económicas al país iraní. 
mano para impartir justicia. Así pues, el filósofo italiano propone indagar por una etiología de la guerra amparada en las posturas de LrenäusEibl- Eibesfeldt y Frans de Waal (Zolo, 2000: 199).

Propone abordar, por un lado la guerra y, por otro, el conflicto, para proponer una nueva forma de comprender las instituciones y su funcionalidad. Para Zolo, la importancia de defender instituciones débiles debe constituir el norte no solo de la reflexión, sino de la intervención política a partir de las cuales se garantice el control de armamentos, donde se propenda por el establecimiento de instituciones de promoción cultural, de resolución y arbitraje de conflictos, todas ellas de naturaleza descentralizadas. El cosmopolitismo contractualista requiere una crítica realista que no puede hablar de exterminar la guerra sino, de medidas análogas correctoras que sean funcionales, que hagan que la agresividad y el conflicto no sean dañinos (Zolo, 2000). Se deben tomar medidas para fomentar un modelo cultural e institucional basado en la inhibición de la guerra.

Las guerras, explica Zolo, son inherentes a los seres humanos, como también lo son los conflictos y la paz (2000). "La violencia es tan vieja como el mundo; cosmogonías, mitologías y leyendas nos la muestran vinculada a los orígenes, acompañando siempre a los héroes y a los fundadores" (Domenach, 1981). Entendido el conflicto, en su aseveración positiva, como una fuerza que impulsa la innovación política y social; y la agresión como parte esencial del ser humano inherente, biológica y evolutivamente. Cuando se hace el señalamiento del otro como enemigo enmarcado en el nombramiento del otro como diferente se abre paso a la desfiguración de la otredad del carácter humano y se usa sobre genuinas armas destructivas. Ahora bien, la evolución demuestra que tendemos a la violencia; que como especie y grupos culturales defendemos la propia identidad colectiva frente a lo externo. Esto es, en últimas, la plasticidad evolutiva del homo sapiens que dicta, lejos de una consideración biológica, que el ser humano como especie se hizo de la cultura. Por tanto, la raíz de la guerra está en la agresividad humana y en su instinto de supervivencia en el espíritu de grupo; de esa manera, la agresividad se convierte en un intento de reducir el temor (2000).

Por ende, al ser la guerra un elemento inherente al ser humano no debe negarse que el conflicto y la guerra misma deben integrarse como elementos constitutivos de la vida. Esto es, reconocer la guerra como elemento evolutivo, 
activar mecanismos de control de la agresión y tratar de comprender por qué en toda la historia la guerra se ha presentado como un elemento evolucionista. Así, afirma Zolo, "la idea subyacente sería trabajar con el conflicto en lugar de imponer soluciones violentas desde afuera" (2000, 206).

\section{XI. ¿Una sociedad Civil Global?}

Ahora bien, hay que acotar que la hegemonía cultural y económica de la burguesía, que garantizó una cooperatividad político-económica europea, y que da luz a los Estados liberales, sigue siendo el presupuesto para impulsar la idea del cosmopolitismo. RalfDahrendorf habla de una Sociedad Civil Global como una alternativa de las instituciones oficiales frente a la interdependencia que caracterizan las problemáticas que se dividen en el orden internacional, ya sea para anteponerse nuevas formas de institucionalidad, o para manifestar una forma de resistencia o activismo. Zolo encuentra problemático hablar de una Sociedad Civil Global como estrategia de integración planetaria. Su postura realista y sus pretensiones de desenmarañar las conjeturas de los cosmopolitas lo obliga a mirar conrecelo, por sobre todo, el tratamiento que se hace a la defensa de sus tesis como solución al intervencionismo humanitario o en sus términos más normativos al constitucionalismo global que, lejos de remediar los problemas de guerra, puede justificar la violación indiscriminada y sistemática de los derechos (Zolo, 2011).

Justificadas en ese juego léxico-político de la posibilidad implícita de estos derechos humanos; de reunir no solamente los fundamentos conductuales de los Estados y los ciudadanos, sino también de elevarse a proposiciones normativas, cuando en su seno aparece todavía rodante la antinomia, por ejemplo, entre los derechos de tipo individuales y sociales con aquellos de tipo económico, o de la tensión siempre presente entre los derechos de comunidades que por su reconocimiento étnico-cultural reconocieron históricamente otro tipo de valores sustanciales: ¿cómo lograr implementarlos sin convertirlo todo en un asunto de voluntad política arbitraria o, en el peor de los casos, en un etnocidio a manos de 
la cultura occidental? La premisa parece ser la evangelización de la democracia y de la política occidental. Es como si los defensores del cosmopolitismo vieran con ojos de extraños, ya que sus valores no entran en el orden político, una postura racionalista a la cual las culturas occidentales han objetado y asumido como forma de resistencia frente a la intromisión de culturas diferentes que amenacen esa estabilidad que les ha permitido mantenerse al tope de la injerencia política.

\section{XII. ¿Tránsito al Cosmopolitismo?}

Las condiciones fácticas de las democracias incipientes obligan a reflexionar sobre la construcción de un nuevo orden global, si dicha construcción es admisible, es necesario que éstas se vean contempladas no como el vertedero de las reverberaciones económicas y políticas sino, antes bien, asumir una actitud comunitaria tal como invita el cosmopolitismo, obliga a inyectar toda actitud propositiva con una alta dosis de ética. Si en las entrañas del cosmopolitismo están las bases de un nuevo orden social incluyente, tal como se espera en su aseveración comunitaria, debe invertirse o, por lo menos, ponerse en entredicho la intensión de convertir dicho gobierno mundial a golpe y espada, bajo la legitimidad, por ejemplo, de las intervenciones pacificadoras humanitarias, contemplando tanto su eficacia real como las consecuencias sociales que a su paso deja sobre las poblaciones civiles, en últimas, los agentes más perjudicados (Zolo, 2011).

El estallido del terror y del hambre, las violaciones sistemáticas de derechos de primer orden, el atentado sobre las infraestructuras institucionales y hasta la suspensión de los servicios sanitarios, son algunas señales de precaución de las repercusiones de las decisiones político-militares, encomendadas, desde lo alto de las potencias políticas (Zolo, 2007). Un proyecto político de tan alta envergadura, por lo menos, obliga a pensar en un estadio de transición de justicia donde fuera de abalanzarse con el rótulo de la hegemonía, y la impresión sistemática de la fuerza, que se prospecte en cambios sustanciales pero paulatinos, en la conformación institucional de las entidades más relevantes a nivel mundial, 
aquellas cuya injerencia y capacidad de acción puedan ramificar esos cambios a los ámbitos y territorios más básicos y alejados de la sociedad que pretende cobijar (Zolo, 2000).

Pensar un cambio en el funcionamiento de las instituciones no puede hacerse en clave negativa, esto es, sobre las falencias visibles de las instituciones más fuertes. Ello sólo trae consigo representar en el escenario una obra cuasi apocalíptica donde, naturalmente, el cambio contundente, se prospecta a su vez como una necesidad imperiosa. Un tratamiento realista, tal como propone Zolo, invita más bien a la cautela frente a las repercusiones ya nombradas de las intervenciones políticas y militares como de sus consecuencias sociales que exigen la proyección de un orden más participativo y vinculante de los sujetos políticos, una aseveración que, jurídicamente, se visualiza como un presupuesto de legitimidad política (Zolo, 2001).

En ese sentido, Zolo propone, antes de defender el nombramiento de un orden jurídico internacional, la búsqueda de una estrategia político-económica que parta de un examen sobre las problemáticas inherentes a la escena internacional (2000). Zolo, alejado de una postura idealista, a la manera de cosmopolitas como Habermas y Kelsen, propone un examen riguroso de las contingencias actuales como insumo sustancial para ajustar, en primer lugar, un cuestionamiento sobre ciertas prácticas políticas de las instituciones internacionales de gran calibre, tales como el Banco Mundial, el Fondo Monetario Internacional, Unión Europea y, a la cabeza, la Organización de las Naciones Unidas para, posteriormente, asumir una actitud propositiva en el direccionamiento de la mejora de las funciones acuñadas a dichas instituciones tales como: el establecimiento de los valores democráticos; la creación de políticas de reivindicación constante de los derechos de comunidades que se han mantenido al margen de las discusiones políticas, la promulgación de políticas económicas que reduzcan el espectro de pobreza entre las diferentes naciones, entre otros (2000).

El modelo que defiende Zolo es un modelo débil; un tránsito del pacifismo cosmopolita a un pacifismo débil, esto es, el establecimiento de una red de instituciones internacionales y regionales orientadas a la comunicación cultural y las identidades, llamadas a garantizar la legitimidad de los diferentes sistemas étnicos, culturales y legales, y a la igualdad de autonomía y soberanía de todas las 
naciones asociadas. En síntesis:

Zolo desarrolla una crítica al globalismo jurídico para lo cual propone su llamado "pacifismo débil", el autor considera que el problema del globalismo jurídico se debe a que el orden y la paz internacional no se pueden garantizar mediante el establecimiento de instrumentos coercitivos, jurídicos, económicos o militares sobretodo mientras persista [la] brecha que cada vez más refleja las desigualdades presentes en el poder, riqueza y recursos científicos-tecnológicos en el ámbito internacional (Moreira, 2011).

Su modelo se sustenta en cuatro tesis normativas (2000) que reflejan las falencias más visibles de las propuestas cosmopolitas en lo que se refieren a los cambios institucionales de los entes transnacionales y, en general, a la configuración de un orden mundial, haciendo énfasis en que su implementación termina por menoscabar la soberanía de los Estados, reduciendo su capacidad decisoria en asuntos de injerencia particular a su mínima expresión; tesis que se anclan en la idea de que el auge de una Sociedad Civil Global carece de fundamento $\mathrm{y}$, con ello, la idea de democracia transnacional basada en dicha sociedad, que es la antesala para inclinarse hacia la propuesta de una intervención débil, o unas relaciones internacionales débiles. Tales tesis son:

\section{a. La primacía del derecho internacional}

La progresiva reducción de la soberanía de los Estados como consecuencia directa del establecimiento de un gobierno mundial donde, naturalmente, los Estados se ven relegados ante el desenvolvimiento de todo el aparato jurídicopolítico de las nuevas supra-instituciones. Esto con unas condiciones específicas.

Trazar y actualizar constantemente un mapa global de los grupos étnicosculturales (...) que se encuentren dentro o fuera de las fronteras de los Estados (...); garantizar una vigilancia permanente de las reivindicaciones políticas, económicas y territoriales de dichos grupos (...); favorecer la interacción directa entre los grupos que exigen reconocimiento (...) y poner 
en práctica una diplomacia preventiva no coercitiva (Zolo, 2000; 210-211)

\section{b. Centralismo jurisdiccional}

Para implementarse es necesario el derecho internacional, esto es, el desarrollo de normas y ordenamientos centralizados para la vigilancia y aplicación coercitiva de la ley. Un centralismo que amenaza con abandonar el cubrimiento de los sujetos jurídicos a cabalidad; un centralismo que, en virtud de su financiamiento institucional reclama, por un lado, el apoyo económico y político de las grandes potencias y, por otro, en lo que se refiere a la legitimidad y mantenimiento de los valores democráticos un espectro de participación política igual al de las naciones incipientes (Zolo, 2000).

\section{c. Pacifismo legal}

Esto es, poner límites a la guerra por medio del desarrollo y la aplicación del derecho internacional positivo a partir de la prohibición legal de la guerra. Este planteamiento demanda formalmente dos aspectos: el primero es el revestimiento del derecho internacional como el medio idóneo para solucionar los conflictos entre los Estados y dentro de ellos, y, el segundo, implementar medidas de resolución de conflictos alejados de la intervención militar.

\section{d. Tesis constitucional global}

La capacidad de las instituciones supranacionales centralizadas para salvaguardar las libertades individuales fundamentales que los Estados no pueden garantizar. Lo que exige el asentamiento de estrategias formales de comunicación entre los Estados y sus instituciones con los entes internacionales donde, a la luz de la institucionalidad de los derechos humanos, se aborde conjuntamente el seguimiento, la vigilancia y sentencia de medidas sobre eventos que violen la practicidad del derecho como fundamento jurídico y democrático (2000).

\section{Conclusión}

Danilo Zolo es un pensador muy actual porque tiene una lectura crítica en la que debate con los puntos más vigentes de la agenda internacional. Zolo es un crítico voraz. A veces puede quedarse solo porque sus denuncias pueden declararse 
temerarias. Sus colegas publican en editoriales muy vendidas. Sus colegas van por las universidades de todo el mundo recibiendo homenajes y doctorados honoris causa porque alaban y pregonan todo aquello que Zolo repele y critica: el lenguaje internacional de los Derechos Humanos; las virtudes de la integración económica; la necesidad de la democracia y las Naciones Unidas más la Unión Europea como paradigmas del modelo cosmopolita necesario y virtuoso por naturaleza.

Zolo parece condenado a quedarse cada vez más solo. Pero su apuesta es un proyecto de vida. Es una voz de largo aliento que no se apaga así las editoriales le den la espalada y los Consejo académicos universitarios prefieran evitarle o nieguen su postulación al honoris causa. Pero quienes hemos tenido la fortuna deconocer su obra, hemos podido advertir a un hombre ya mayor que goza de una paz interior; de una libertad moral ilimitada y por eso es insobornable. No escribe pensado en los proyectos editoriales, sino que escribe porque siente que tiene algo qué decir y debe decirlo. Siente que debe usar su condición de profesor universitario y su rol de académico para hacer denuncias. Poner el dedo en la llaga y denunciar. Ha levantado sus banderas en pro de la libertad del disenso y de la crítica. Ha usado la pluma para defender la libertad, la independencia y la dignidad. Ha usado el papel y no los fusiles como sí lo hacen sus objetos de crítica. Ha dicho lo que sentía con una fuerza que no acepta ambages ni excusas. Su voz y su fuerza vital cobran más aliento en épocas en que la ciudadanía vierte sus votos hacia los nacionalismos, el proteccionismo y la exclusión de lo externo. Zolo disfruta en silencio sus victorias intelectuales, pero reconoce con dolor que es culpa del mismo modelo excluyente y solapado de las grandespotencias el que ha despertado el odio, la venganza y la exclusión. Este texto ha sido un pretexto para mirar el mundo, nuestra época y sus fracturas a la luz del pensamiento de Danilo Zolo. 


\section{Bibliografía:}

Baldassarre, A., (1999) La sovranitádal cielo allaterra, en Cazzaniga, G. M. (ed.), Metamorfosidellasovranità. Trastatonazionale e ordinamentigiuridicimondiali, Pisa: Edizioni ETS

Banco Mundial, (2015). Pobreza: panorama general. Recuperado en abril 10 de 2016 de http://www.bancomundial.org/es/topic/poverty/ overview

Basombrío, C. et al (2013). Seguridad y populismo punitivo en América Latina: Lecciones corroboradas, constataciones novedosas y temas emergentes. Washington D.C.: Wilson Center. Recuperado en mayo 22 de 2016 de https://www.wilsoncenter.org/sites/default/ files/Seguridad\%20y\%20Populismo\%20Punitivo $\% 20$ en $\% 20$ America\%20Latina.pdf

Bobbio, N., (1984) El problema de la guerra y las vías de la paz. Barcelona: Gedisa

Bobbio, N., (1991) El tiempo de los derechos. Madrid: Editorial Sistema Bobbio, N., (2006) El problema del positivismo jurídico. Traducción castellana de Ernesto Garzón Valdés, Editorial Universitaria de Buenos Aires, Argentina, 1965 (reedición mexicana en Fontamara, México, 1991).

Bremer, J.J. (2013). De Wesfalia a post-Wesfalia. Hacia un nuevo orden internacional México: Universidad Nacional Autónoma de México. Bull, H., (1977). The anarchical society. New York: Columbia University Press.

Campione, R. (2009). El nomos de la guerra. Valencia: Tirant Lo Blanch. Castro, C., (2015). No tiene ningún sentido condicionar la justicia transicional a la cárcel. Colombia: Revista Semana. Recuperado en mayo 22 de 2016 de http://goo.gl/YEQczf.

Castro, S. (2009). La Justicia de los vencedores. De Nuremberg a Bagdad. En Revisa SAAP, Vol. 3, Número 3 (p. 731 a 734).

Centro Nacional de Memoria Histórica (2013). ¡Basta ya! Colombia: Memorias de guerra y dignidad. Bogotá: Imprenta 
Nacional. Recuperado en mayo 22 de 2016 de http://www. centrodememoriahistorica.gov.co/descargas/informes2013/bastaYa/ bastaya-colombia-memorias-de-guerra-y-dignidad-2015.pdf.

Centro Nacional de Memoria Histórica (s.f.). Los proceso de paz con el M-19, el EPL, el Quintín Lame y el PRT desde 1989 a 1991. Recuperado en mayo 22 de 2016 de http://centromemoria.gov.co/ wpcontent/uploads/2014/11/Los_proceso_de_paz_con_el_M.pdf.

Comité Internacional de la Cruz Roja (1949). Convenios de Ginebra. Recuperado el 13 de marzo de 2016 https://www.icrc.org/spa/warand-law/treaties-customary-law/geneva-conventions/overviewgeneva-conventions.htm

Corte Interamericana de Derechos Humanos (s.f.). Cuadernillo de Jurisprudencia No 7: Control de Convencionalidad. Recuperado el 4 de abril de http:/www.corteidh.or.cr/sitios/libros/todos/docs/ controlconvencionalidad8.pdf

Corte Penal Internacional (1998). Estatuto. Roma.

Cotes C., et al). (s.f.). Populismo punitivo: incidencia actual en el contexto legislativo colombiano. Revista Actualidad Jurídica. Tercera y cuarta edición. Recuperado el 6 de mayo de http://goo.gl/Lk0PQN

Cubas, J. M. (1994). La teoría postempirista de la democracia de Danilo Zolo: Una aproximación. Revista de estudios políticos (Nueva Época) No. 84. Recuperado el 20 de febrero de https://dialnet. unirioja.es/descarga/articulo/27264.pdf

D. Grimm, (1996) Una Costituzione per l'Europa, en G. Zagrebelsky et al. (eds.), Il futuro dellaCostituzione, Einaudi, Torino. Págs. 339367.

Donais, T. (Febrero de 2011). ¿Empoderamiento o imposición? Dilemas sobre la apropiación local sobre los procesos de construcción de paz. En Relaciones internacionales. Construcción de paz posbélica y construcción del Estado, Núm. 16.

Domenach, J.M., (1981) La violencia. En: La violencia y sus causas. Editorial de la Unesco. Recupera el 20 de febrero de http://unesdoc. unesco.org/images/0004/000430/043086so.pdf 
Habermas, J. (1999). La inclusión del otro. Estudios de teoría política. Barcelona: Paidós

Habermas, J. (2000). La constelación posnacional. Buenos Aires: Paidós Helleiner, G., K. (1992) The New Global Economy and the Developing Countries

Kant, I., (1795). Sobre la paz perpetua. Tecnos. (2005). Madrid.

Kelsen, H., (1944). Peace through law. Chapel Hill. The University of North Carolina Press.

Kelsen, H., (1952). Principles of international law. New York: Rinehart $\&$ Company, Inc.

Kelsen, H., (1960). La Teoría Pura del Derecho. Buenos Aires (2006): Editorial Universitaria de Buenos Aires

Kelsen, H. (s.f.). Das Problem der Souveränität und die Theorie des Völkerrechts., (pág. 196 y sig).

Maldonado, J., (2013) El rol de la Corte Constitucional en la garantía del derecho a la paz. Pág 281-296. Recuperado en abril 10 de 2016 de http://cienciasjuridicas.javeriana.edu.co/documents/3722972/ 4350738/13+El+Rol+de+la+Corte+Constitucional+281-296.pdf/ f1959f23-f1dd-406b-950f-f6b9512a24f0

Negri, A. (2002) Imperio. Barcelona: Paidós.

Negri, A. (2004) Guías. Cinco lecciones en torno a Imperio. Barcelona: Paidós.

Novaro, N. et al, (2003). La dictadura militar (1976-1983). Del golpe de Estado a la restauración de la democracia. Buenos Aires: Paidós. Organización de las Naciones Unidas, (1992). Un programa de paz. Asamblea General y Consejo de Seguridad de la ONU. Recuperado en febrero 16 de 2016 de http://www.un.org/es/comun/ docs/?symbol $=\mathrm{A} / 47 / 277$

Organización de las Naciones Unidas. (1948). Declaración Universal de los Derechos Humanos. Recuperada en mayo 18 de 2016 de http:// www.un.org/es/documents/udhr/

Organización de las Naciones Unidas. (2015). Objetivos de Desarrollo del Milenio. Informe de 2015 Recuperado en mayo 22 de 2016 de 
http://www.un.org/es/millenniumgoals/pdf/2015/mdg-report-2015_ spanish.pdf

Organización de las Naciones Unidas. (s.f.). Historia de las Naciones

Unidas Recuperada en mayo 18 de 2016 de http://www.un.org/es/ sections/history/history-united-nations

Pagano, F. M. (s.f.) El problema de la verdad en materia panal. En

Revista Pensamiento Penal.Texto recuperado el 15 de enero del 2016 del sitio web: http://www.pensamientopenal.com.ar/system/ files/2015/06/doctrina41357.pdf.

Sartori, G., (1997). Homo Videns. La Sociedad Teledirigida. Roma. Taurus. Pensamiento.

Walzer, M., (1997) Guerras justas e injustas. Un razonamiento moral con ejemplos históricos. Barcelona: Paidós

Zolo, D. (2000). Cosmópolis: perspectiva y riesgos de un Gobierno Mundial. Barcelona: Paidós.

Zolo, D. (2001). Los fundamentos de los derechos fundamentales. En L. Ferrajoli (Ed.), Libertad, propiedad e igualdad en la teoría de los derechos fundamentales. A propósito de un ensayo de Luigi Ferrajoli (págs. 75-104). Madrid: Editorial Trotta.

Zolo, D., (2002). Una crítica realista del globalismo jurídico desde Kant a Kelsen y Habermas. Anales de la Cátedra Francisco Suárez. Número 36- 2002, pág. 197-218.

Zolo, D., (2004). El terrorismo tomado en serio. Metapolítica. Volumen 8 , número 37.

Zolo, D., (2006). Globalización: un mapa de los problemas Bilbao: Ediciones Mensajero.

Zolo, D., (2006a). ¿Reformar las Naciones Unidas? En Revista Foro, número 58, p. 107-120

Zolo, D., (2007). La justicia de los vencedores: de Nuremberg a Bagdad Barcelona: Madrid: Editorial Trotta.

Zolo, D., (2011). Terrorismo Humanitario. De la guerra del Golfo a la carnicería de Gaza. Barcelona: Edicions Bellaterra 
